\title{
FDA and surrogate endpoints in Alzheimer's disease
}

Not only is the attrition rate for Alzheimer's disease therapeutics notoriously high, but also any company hoping to bring a drug to market faces a further layer of uncertainty: how open will the FDA be to new ways of proving efficacy for drug candidates? In March, Russell Katz, director of the agency's neurology products division told a meeting of the coalition to Accelerate Cure/Treatments for Alzheimer's Disease that Alzheimer's disease Assessment Scale cognitive subscale (ADAS-cog), long the standard in Alzheimer's disease measures, might not be required to prove a therapy works. He said the same about the Clinician's Interview-Based Impression of Change plus caregiver interview, another common gauge. Some had worried that the FDA might look less fondly on such tests as the Neuropsychological Test Battery (NTB), but Katz's remarks seemed to indicate the bar may be lowered, or criteria at least potentially relaxed.

Much talk at the meeting - which brought Alzheimer's disease researchers "one of our few documented insights" from the FDA, analyst Brian McCarthy with Merriman Curhan Ford in New York says - had to do with the bottom-line demand for showing improvements in global functions, such as those covered by the Disability Assessment for Dementia scale and Clinical Dementia Rating Sum of Boxes (CDR-SB), as well as boosts in cognitive abilities, such as those measured by NTB and ADAS-cog. "You can make somebody an Einstein, but if you haven't improved the globalfunction score, the FDA isn't going to be interested," he says.

The agency's willingness to accept new endpoints could make or break some up-and-coming drugs, Marwan Sabbagh, staff physician at Boswell Memorial Hospital in Sun City, Arizona, says. He cites Indianapolis-based Eli Lilly's LY2062430 currently in phase 2 trials. The compound is designed to inhibit $\beta$-secretase. But according to Sabbagh, the uncertainty surrounding the disease mechanism is what complicates surrogate markers in Alzheimer's disease compared with other indications. "The ultimate study is hypertension-you give [patients] a drug, their blood pressure goes down, and this means the drug works," he says. Ideally, the Lilly compound would have a similarly straightforward effect on amyloid plaque in the brains of Alzheimer's patients. "Lilly could show they give the drug and amyloid goes down, but we [wouldn't] know what that means," he says. "What if amyloid goes down and ADAS-cog doesn't move? Is that a negative? Does the drug work?"

Scott Turner, director of the memory disorders program at Georgetown University Medical Center, says ADAS-cog and CDR-SB, as cognitive and functional tests respectively, "were never set in stone." For example, New York-based Forest Laboratories' Namenda (memantine), an $\mathrm{N}$-methyl-D-aspartate antagonist for moderate to severe Alzheimer's disease, was approved in October 2003 on the basis of trials that did not use ADAS-cog. Turner-who is involved in the phase 3 bapineuzumab trial, among others-says further flexibility of regulators in considering measures with real-world value can only help patients, as well as drug developers. Wider use of biomarkers, such as Pittsburgh Compound-B positron emission tomography imaging, could prove beneficial, too, he says.

The question of what determines efficacy for the FDA is "in flux, and it's good that it is," Turner says. No matter what the endpoints, "there are going to be a lot of negative trials - that's the nature of this business-but I think we're getting closer" to a viable drug, he adds. Sabbagh agrees and suggests that more about the disease could be learned by detecting and treating patients earlier, when they show mild cognitive impairment. Spinal-fluid proteins might be useful as another potential marker, along with imaging. "That would be a paradigm shift," Sabbagh says. "I think we need to go down that road."

\section{Details}

Immunomedics will grant Nycomed an exclusive, worldwide license to develop and commercialize veltuzumab for noncancer indications. Nycomed plans to develop the humanized antibody targeting CD20 as the primary indication for immune thrombocytopenia purpura. Immunomedics will receive $\$ 40$ million up-front and be eligible for $\$ 580$ million in milestones, plus escalating double-digit royalties.

Alnylam granted Kyowa exclusive rights to develop and commercialize ALN-RSV01. The respiratory syncytial virus (RSV) specific short interfering RNA (siRNA) is currently in phase 2 trials for RSV infection. Under the deal, Alnylam receives $\$ 15$ million up-front and is eligible for $\$ 78$ million in milestones, plus double-digit royalties.

Crucell entered a nonexclusive license agreement for Bioceros' STAR technology for the production of recombinant human antibodies and proteins. The STAR platform enables stable and high-yield gene expression boosting production yields using serum-free media.

Thrombogenics and Biolnvent entered an exclusive license agreement with Roche for their jointly developed T-403, a humanized anti-cancer monoclonal antibody that blocks placental growth factor involved in new blood vessel formation. ThromboGenics and Biolnvent will receive an upfront $\$ 78.4$ million from Roche and up to $\$ 705.2$ million based on successful completion of commercial milestones as well as double-digit royalties on potential product sales. Thrombogenics, which discovered TB-403, will receive $60 \%$ and Biolnvent $40 \%$ of the deal revenues.

AMT has in-licensed an advanced small nuclear RNA (snRNA)-based exon skipping technology from La Sapienza University. AMT will combine their proprietary adeno-associated virus gene therapy platform with the snRNA technology to develop a single-shot treatment for Duchenne Muscular Dystrophy.

Senesco has entered two separate deals related to its combination therapy with Factor 5A gene and siRNA against Factor 5A. Senesco has contracted VGXI to supply the plasmid portion and Polyplus-transfection, the jetPEI for systemic delivery. The therapy is in preclinical development against multiple myeloma.

\section{IN their words}

\section{"The lobbyists said jump and unfortunately,} Beacon Hill says, 'How high?'”

Senator Mark Montigny, a New Bedford Democrat, on the removal of language banning drug industry gifts and free meals for doctors from a bill in the Massachusetts state legislature. (Wall Street Journal Blog, July 16, 2008)

\section{"My guess is that 20 years from now if you look backwards, $90 \%$ of the value of these cells will be in things that don't make the front page."}

James Thomson of the University of Wisconsin, Madison, and startup Cellular Dynamics, on how using cardiac cells derived from human embryonic stem cell lines for safety testing could be used in drug development. (Forbes, June 16, 2008)

\section{"Perhaps having renal dialysis or going blind is worse than dying suddenly, which is quick, cheap and painless."}

Schering-Plough's Enrico Veltri argues that the FDA's vote to require further testing for cardiac side effects in diabetes drugs would slow development. (Forbes, July 7, 2008) 